\title{
Encephalopathy following a sting
}

\author{
BRYAN ASHWORTH \\ From the Bristol Royal Infirmary
}

Death following a sting is a rare event. It usually occurs within half an hour of a wasp sting, and if this period is survived full recovery is the rule. This paper describes two cases of severe acute encephalopathy which developed within a few hours of a sting. The patients recovered almost completely but some evidence of cerebral damage remained.

\section{CASE REPORTS}

CASE 1 The patient was a married woman of 37 years (BRI 025606). She had been well until 11 September 1963. On that day her husband returned home and found her slumped in a chair, staring vacantly, and mute. She was immobile, had vomited, and had also been incontinent of urine and faeces. There was nothing of note in the previous medical history and no past history of a sting. Her husband noticed an area of redness of the skin of the left forearm which he thought was due to a sting but no insect could be found.

She was admitted to the Bristol Royal Infirmary and was found to be obese, with blood pressure $120 / 70 \mathrm{~mm}$. $\mathrm{Hg}$ and pulse rate $100 /$ minute. She made no response to question or command but she resisted movement of her limbs. The pupils were equal and reacted to light but she was unresponsive to movements in front of the eyes though the eyes were open. The tendon jerks were increased in all limbs but more on the left side. The plantar responses were flexor. A small erythematous lesion was noted on the left forearm.

On the following day the blood pressure was recorded as $90 / 60 \mathrm{~mm} . \mathrm{Hg}$, the eyes moved slightly, and she would look in the direction of persons speaking to her.

On the third day she was able to say 'yes' and 'no' but she appeared 'far away' and broke down easily. The lesion on the left forearm had become indurated. In addition she had weakness of the right lower face, which cleared if she smiled, impaired movement in the right upper limb, dysarthria, and an incomplete right homonymous hemianopia.

She improved gradually. Nine days after admission prednisone was started in a dosage of $60 \mathrm{mg}$. daily. Within two days improvement was striking. Conversation became possible. The right upper limb remained weak and she was unaware of its position. She repeatedly confused left and right. She tended to put on her dressing gown inside out and was unable to tie the girdle of it.

When examined on 4 October 1963 (23 days from the onset) she cooperated well and was able to state the month and year. Speech was hesitant and slightly dysarthric.
The facial weakness had cleared but there was still as incomplete right homonymous hemianopia. The tendog jerks were all obtained and the plantar responses flexo모 Position sense was impaired in all limbs but power was full. She had difficulty in initiating any movement whethed spontaneous or requested, and particularly in writing which was only possible with the left hand though she haw previously been regarded as right handed. Her writing 謨

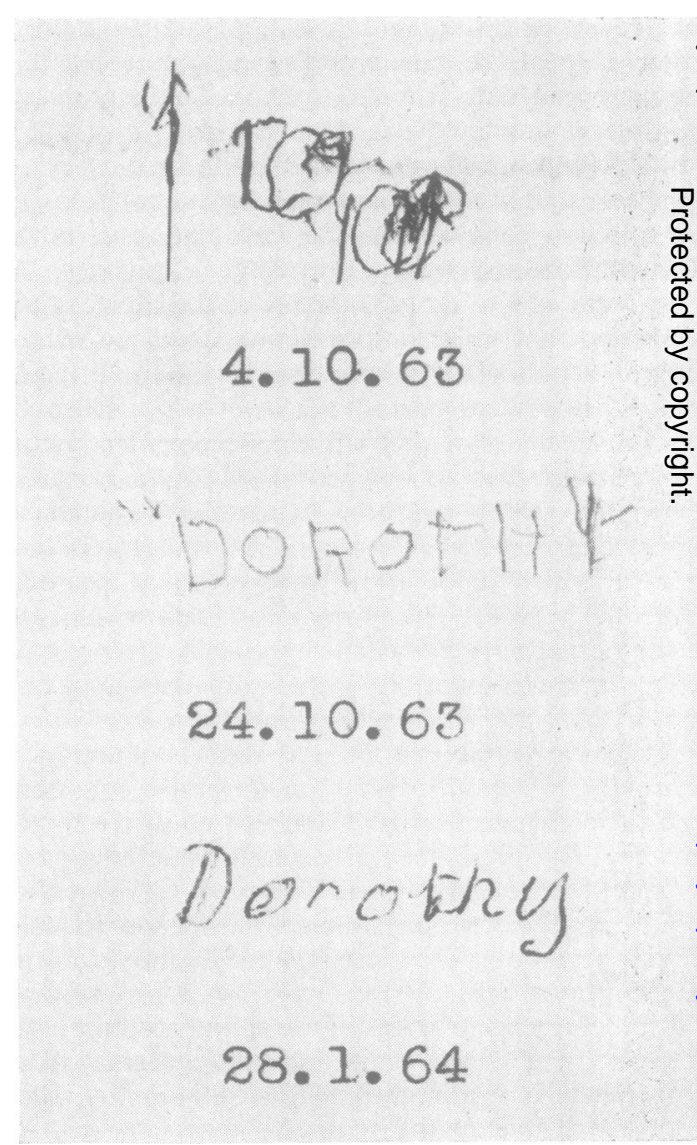

FIG. 1 Writing of the patient's own Christian name. a. After three weeks

b. After six weeks

c. After 18 weeks. 


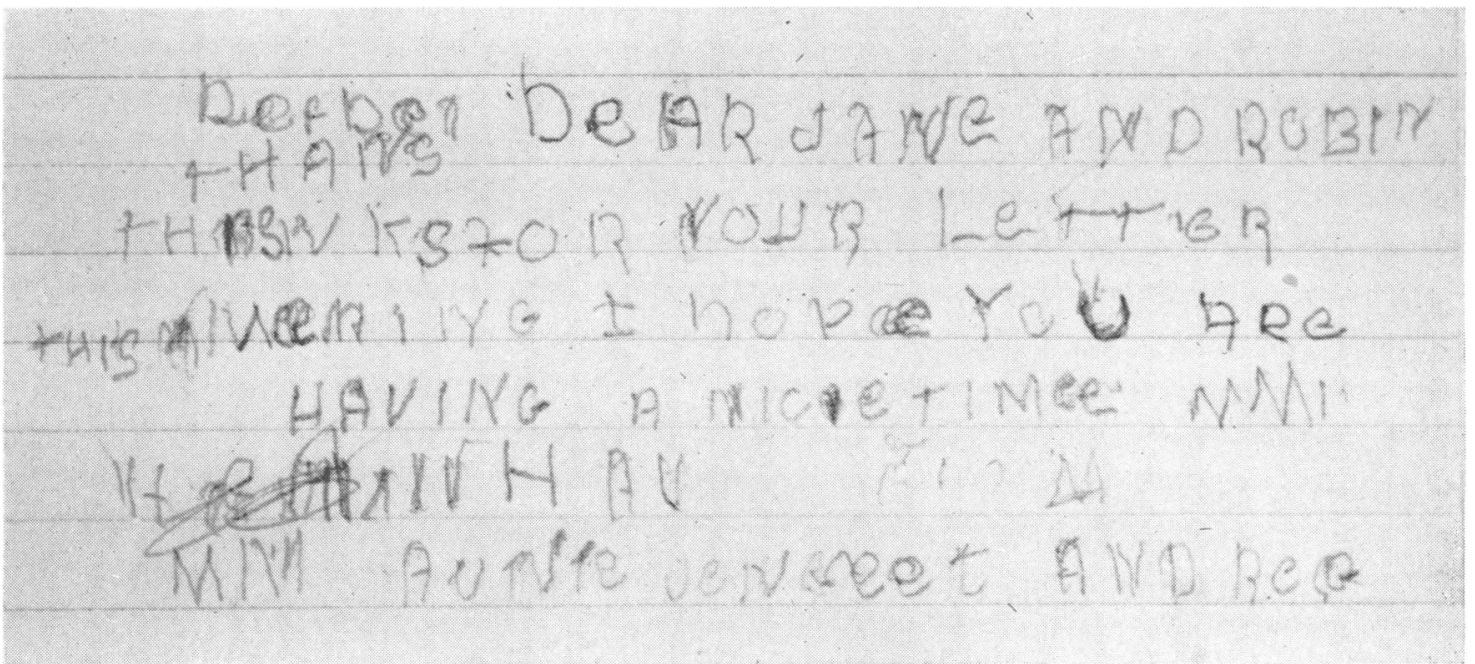

FIG. 2 Letter written six weeks after the onset.

this stage was undecipherable (Fig. 1a). She could not copy simple patterns, nor arrange four matches in a square after demonstration. An attempt to draw a clock face resulted in two linear marks on the paper and the placing of towns on the map of England was grossly inaccurate. The simplest calculation was impossible. She was unable to distinguish right from left and could not identify her fingers. Reading was not affected.

Shortly afterwards she tried to arrange some flowers in a vase and put the heads in the bottom of the vase. She realized that they were wrongly placed but even after great effort she was unable to arrange them correctly.

Seven weeks after admission she was discharged home.
By that time the hemianopia had cleared and speech was normal. Writing with the left hand had improved and also spatial orientation. She was able to lateralize but still had difficulty in calculation and manipulating money. After her return home she had difficulty in arranging crockery on a plate rack in the inverted position. She tried to fold linen sheets with the help of a friend but agreement over the method of doing so proved impossible.

In December 1963 she was able to do her Christmas shopping alone but found working out the cost difficult.

Five months after the onset she had improved further and was able to return to part time work.

After six months she was readmitted to the ward with

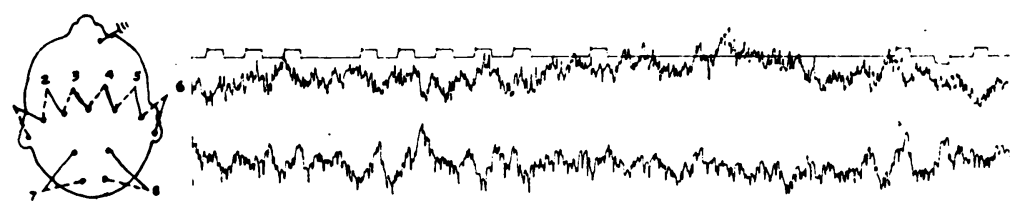

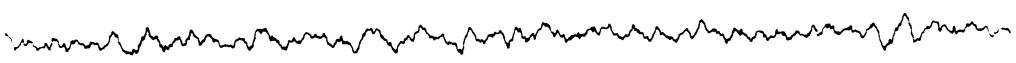

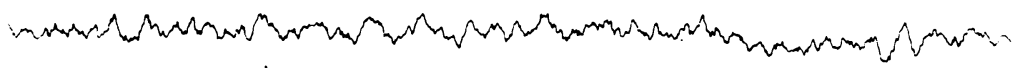

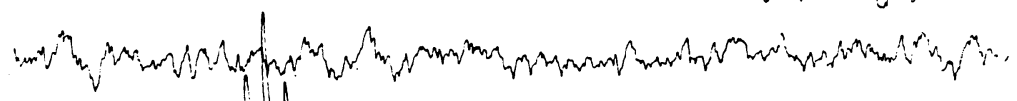

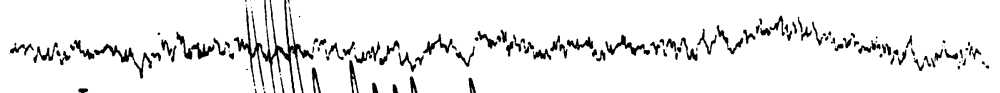

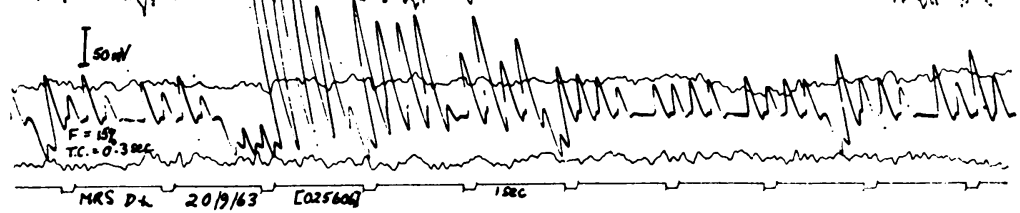

FIG. 3a. E.E.G. nine days after onset of illness. 


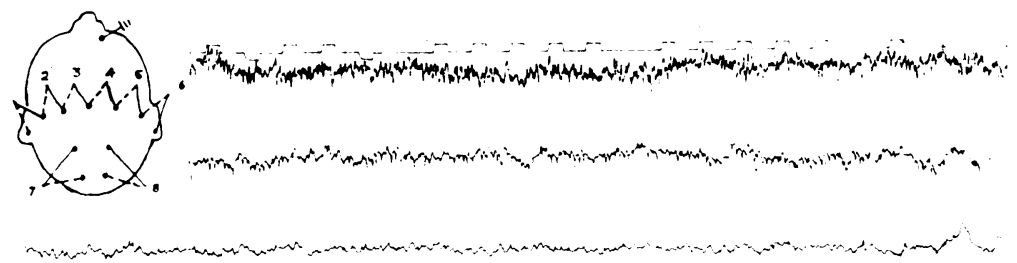

FIG. $3 \mathrm{~b}$ E.E.G. 16 days aft

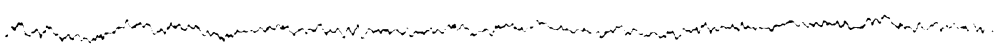
onset of illness.

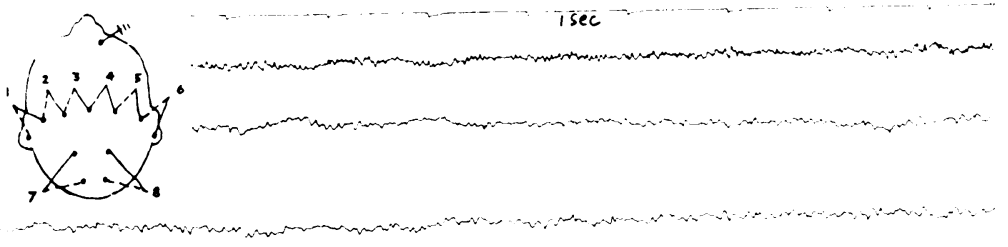

FIG. 3c E.E.G. 16 weeks onset of illness.
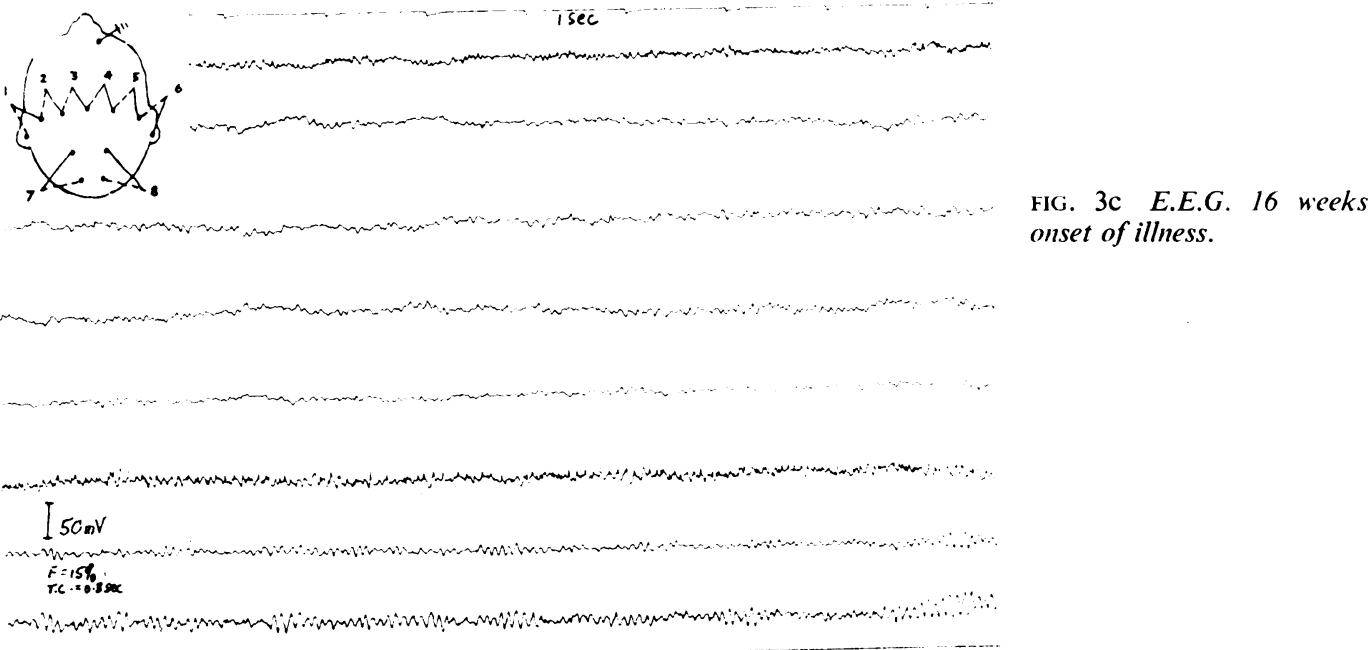

a view to desensitization. No abnormal physical signs were found. Writing had improved but was slow and her ability to add and subtract was impaired. No disturbance of spatial orientation could be demonstrated. The match tests were carried out satisfactorily. Intradermal tests using preparations of wasp and bee venom (Bencard) were negative.

Investigations The cerebrospinal fluid was under normal pressure. On 12 September it contained 1 cell/ c.mm., protein $33 \mathrm{mg} . \%$, and four days later 3 cells/ c.mm., protein $40 \mathrm{mg} . \%$. The Wassermann reaction and Large curve were negative.
A blood count on 13 September gave haemoglobi $13.1 \mathrm{~g} . \%$, white cell count $16,000 / \mathrm{c} . \mathrm{mm}$., with a polg morph leucocytosis. The B.S.R. was $25 \mathrm{~mm}$./hour. (Wintrobe). On 18 September the white cell count w8ु $9,400 /$ c.mm. The blood Wassermann reaction was negative and a random blood sugar estimate gave $105 \mathrm{mg} . \%$ Blood cultures were sterile. Plasma proteins were norma $\$$.

Radiographs of the chest and skull were normat Serum glutamo-oxalo-acetic transaminase was 2 units $/ \mathrm{m}$. Culture and virus studies in cerebrospinal fluid were negative.

Electroencephalography On 20 September 1963 the 
record was grossly abnormal, with diffuse slow wave activity, but no focal abnormality (Fig. 3a). A week later slow waves were much less marked but were present over the temporal areas and more marked on the left side (Fig. 3b), and on 18 October a similar record was obtained. On 2 February 1964 the trace showed asymmetrical alpha rhythm with low amplitude over the left temporal and parietal regions (Fig. 3c).

CASE $2^{1}$ A man of 40 years was admitted to hospital following an insect sting. He had marked oedema of the head and neck and was unconscious on admission. During the next week he slowly recovered consciousness. His vocabulary was limited and he had to learn to read and write again. Two years after the incident intellectual impairment was still considerable. Later he was able to return to office work but found difficulty in carrying it out. Evidence of impaired cerebral function has persisted.

\section{DISCUSSION}

The nature of the sting is uncertain in these cases; no insect was found. The extent and persistence of the lesion of the skin in case 1 suggest that it was caused by a wasp or a bee.

Wasp venom contains at least three substances in high concentration: histamine, 5-hydroxytryptamine, and an unidentified smooth muscle stimulant (Jaques and Schachter, 1954). Bee venom contains a protein, melittin, a powerful dehydrogenase inhibitor, and a hyaluronidase (Hodgson, 1955).

A detailed review of the pathological effect of wasp and bee stings is given by Marshall (1957). He describes one case of sudden death with post-mortem examination following a wasp sting but does not comment on the central nervous system. Jensen reviewed the literature of cases with sudden death following a wasp or bee sting and found 30 reports up to 1961, including four of his own. He found oedema of the glottis, pulmonary emphysema, visceral congestion, and haemorrhages into skin, mucous membrane, and serous membranes. He concluded that most deaths were due to anaphylactic shock (Jensen, 1962).

An important contribution to the neurological aspects of these cases is made by Day (1962). He describes the case of a man of 36 years with 60 stings on the neck. Within an hour the patient developed convulsions and a right hemiplegia. Cortisone and antihistamines were administered. Necropsy revealed softening of the left cerebral hemisphere and a haemorrhagic infarct in the parietal region with associated pontine haemorrhage. The lungs contained frothy blood-stained fluid. In addition he quotes seven cases from the literature with lesions

'I am grateful to Dr. Bengt Ihre for allowing me to report the essential details of a similar case seen by him in Stockholm. of the central nervous system. The usual findings were oedema, intraventricular haemorrhage, and petechiae. He also comments that the lesions were similar to those found experimentally in anaphylactoid reactions. He concludes that death was often due to anaphylaxis caused by foreign protein.

The pathogenesis of these changes is not fully understood but several factors probably contribute. Hypersensitivity to protein substances in the sting may be due to idiosyncracy or to sensitization from a previous sting. The dose of venom is clearly proportional to the number of stings and in several fatal cases there were multiple stings. It is possible that venom may be directly injected into a vein and this, of course, is more likely when there are many stings. Sensitivity may provoke a generalized vascular reaction and this in turn may cause hypotension. A profound fall in blood pressure may contribute to the cerebral lesions. The lowest blood pressure recorded in case 1 was $90 / 60 \mathrm{~mm}$. $\mathrm{Hg}$ and this was on the day following admission at a time when the cerebral lesions were already present. It remains possible that there was a period of hypotension before she reached hospital.

Reports of persisting symptoms or residual neurological deficit are scant. Roch reported the case of a young man who became comatose after a severe wasp sting and came round after three days. He remained aphasic and hemiplegic (Roch, 1926). Roch also quotes a case described by Mabaret du Basty (1819) of a man of 46 years who was stung on the back of his hand by a wasp. He developed a sensation like an electric shock with swelling of the arm. The conjunctiva was injected and he tended to fall asleep. A similar event had occurred five years previously (Roch, 1928).

It is clear that at the onset of the illness in case 1 there was a severe disturbance of cerebral function and it is possible from clinical and E.E.G. evidence that diffuse neuronal involvement occurred. Alternatively multifocal lesions in the hemispheres and brain-stem may have been present as in one case reported by Day (1962). A third possibility is diffuse encephalopathy with focal neuronal damage. Clinically, in case 1 the striking feature of the recovery was the rapid restoration of speech, the more gradual return of spatial orientation, and the much slower return of writing and ability to make calculations. Six months from the onset the patient still shows disturbance of these functions. The mode of recovery suggests that the ability to write and to do calculations has recovered by a process of relearning rather than by reconstitution of mechanisms previously present. In this connexion the writing is of interest (Figs. 1 and 2), and resembles that of a child learning to write. 
After six months it was thought advisable to consider desensitization with venom in case 1 . As a preliminary, skin tests were done, cautiously starting with weak solutions. No skin sensitivity to wasp or bee venom could be demonstrated. It is possible that the patient desensitized herself during the illness or alternatively that some other insect caused the sting.

\section{SUMMARY}

Two cases of severe encephalopathy following a sting are reported. The patients both virtually recovered but had persisting neurological deficits. The possible mechanisms of pathogenesis and recovery are discussed.

I am grateful to Dr. A. M. G. Campbell for allowing me to report case 1 and for his help in obtaining details of case 2. I also wish to thank Dr. P. K. G. Warren for the electroencephalograms.

REFERENCES

Day, J. M. (1962). Death due to cerebral infarction after wasp stingsD Arch. Neurol. (Chic.) 7, 184-186.

Hodgson, N. B. (1955). Bee venom: Its components and their propero ties. Bee Wld, 36, 217-222.

Jaques, R., and Schachter, M. (1954). The presence of histamine 5-hydroxytryptamine, and a potent, slow contracting substanec in wasp venom. Brit. J. Pharmacol., 9, 53-58.

Jensen, O. M. (1962). Sudden death due to stings from bees and wasp $\overline{\bar{F}}$ Report on 4 new cases, 3 with autopsy. Acta path. microbio? scand., 54, 9-29.

Mabaret, du Basty, P. G. (1819). Bibliothèque méd., 66 quoted bf Roch, M. (1928)

Marshall, T. K. (1957). Wasp and bee stings. Practitioner, 178, 712 722.

Roch, M. (1926). Report of Meeting of the Société Médicale de Genève, January 1926. Revue méd. Suisse rom., 46, 574-575. (1928). Les picû es d'hymenoptères au point de vue clinique et
. therapeutique. Ibid., 48, 913-950. 